\title{
BOTTOM-NETS AS A NEW METHOD FOR QUANTITATIVELY SAMPLING TADPOLE POPULATIONS (AMPHIBIA, ANURA)
}

\author{
Claude Gascon ${ }^{2}$
}

\begin{abstract}
A new technique to reliably estimate true tadpole abundance in small ephemeral forest ponds based on a sample taken from a bottom net is presented. The bottom net is placed in the pond before it fills with water. At given intervals the bottom net is lifted through the water column and all tadpoles can be counted. Based on a series of calibrations, the technique showed significant correlations between estimated abundance of Osteocephalus taurinus Steindachner, 1862, Colostethus marchesianus Melin, 1941, Phyllomedusa tomopterna Cope. 1868, and aeshnid larvae, and true abundances based on total counts.
\end{abstract}

Few reliable methods exist to quantitatively sample tadpole populations. HEYER $(1973 ; 1976 ; 1979)$ used a standard number of sweep nets to estimate year to year changes in tadpole abundance in one site.

Others used a vertical sampler (an open-ended cylindrical PVC tube placed vertically in the water column) to examine habitat-use by various tadpole species (AlFORD \& CRUMP 1982; ALFORD 1986). These techniques are adequate for estimating relative abundances or spatial patterns of habitat use in a given site. However, because few samples are taken at any one time and no calibration of the technique is performed (comparison with true total abundances) one cannot extract estimates of total tadpole abundance in a pond. Mark-recapture methods of tadpoles have been devised to address this drawback. Tadpoles are marked either by tail clipping (TURNER 1960) or by staining (HERREID \& KINNEY 1966; GUTTMAN \& CREASEY 1973; SEALE \& BoraAs 1974) and total abundances are estimated by standard recapture techniques. For long-term studies, however, tail clipping and some staining techniques are inadequate because marks are short-lived (maximum of two weeks; TURNER 1960). Other marking methods are time-consuming and involve extensive handling of the tadpoles (SEALE \& BORAAS 1974). These drawbacks often limit the number of sites that can be effectively sampled. An efficient, rapid, and standardized methodology for quantitatively sampling tadpole populations at a large number of sites is desirable in order to 1) compare total abundances at many sites through time, 2) evaluate total abundances to provide accurate density estimates for various species at various sites, and 3) calculate survivorship curves based on total abundances.

The purpose of this paper is to report on a new methodology for quantita-

1) Publication number 116 of the Biological Dynamics of Forest Fragments Project.

2) Department of Zoology, University of Guelph, NIG 2WI Guelph, Ontario, Canada.

Present address: Ecologia/INPA, Caixa Postal 478, 69011-970 Manaus, Amazonas, Brazil. 
tively sampling tadpole populations in isolated forest ponds. The method consists in placing bottom-net samplers in ponds before they till with water. Samples are then taken at appropriate frequencies to estimate tadpole abundance. Regression analysis is then used to compare exhaustive total counts of tadpoles in a pond to samples taken with the bottom-net after correcting for surface area sampled. The regression equation obtained permits the estimation of total ahundance from net samples. Both the bottom net sampler and the statistical analyses are described in detail.

\section{MATERIALS AND METHODS}

\section{STUDY SITE}

Work was carried out in the Instituto Nacional de Pesquisa do AmazonasSmithsonian Institution (INPA-SI) reserves, $80 \mathrm{~km}$ north of Manaus (2 $30^{\circ} \mathrm{S}$. $60^{\circ} 0^{\prime} \mathrm{W}$ ), Brazil. The forest in the area is typical terra firme forest (not subject to periodic flooding); canopy height is less than $40 \mathrm{~m}$, and palms dominate the understory. Twelve isolated forest ponds were selected in the area, and bottom-net samplers were placed in each site (see next section for details of the sampler). Sites were usually small $\left(<20 \mathrm{~m}^{2}\right)$ with leaf litter or grassy suhstrates and occasional muddy areas. Water was clear to slightly turhid and only one site was permanent. Sites were either upland terra firme or lowland stream-associated (see GASCON 1991, for details of site characteristics). Sites were repeatedly sampled for two years to estimate total ahundances of tadpole species and their predators (see GaSCON 1991, for details of the sampling frequency).

\section{BOTTOM NET SAMPLER}

Bottom-net samplers were constructed of nylon mesh screening attached to a wooden frame. All nets measured $2.5 \mathrm{~m}$ wide and $1 \mathrm{~m}$ long. The screening was slightly wider than $1 \mathrm{~m}$ so that the net would actually have a pocket when attached to the wooden frame. These nets were placed in the bottom of ponds during the dry season. When ponds filled with water, the hottom-nets could he rapidly lifted through the water column (one person securing the net at each end) and placed on dry ground. At this point all material was removed from the bottom-net and sorted to species of tadpoles and predators. The number of individuals of each species (tadpoles and predators) was noted and the animals were placed in a bucket of water until their return to the pond.

In order to calibrate net samples. exhaustive samples of tadpole populations were made at various times throughout the two years of the study. Six such calibrations were performed at different times in different sites. Each calibration consisted in taking the regular hottom-net sample in a site and then exhaustively sampling the entire tadpole community with dip-nets, seines, and strainers. To do this, two people spent as much time as necessary sampling the pond with dip-nets. This was continued until $15 \mathrm{~min}$ had elapsed without catching any tadpoles. Completion of this whole process usually required approximately two hours. The total catch was then sorted hy species, counted, and replaced in the pond. At each 
visit, width and length of the pond were measured to evaluate the proportion of the entire surface area that the bottom-net was sampling.

\section{STATISTICAL ANALYSES}

Correlation analysis was performed between estimated total abundance from the bottom-net samples and the true total abundance as determined from the exhaustive samples. Pearson correlations were calculated for each species independently from six bottom-net estimates and their corresponding true total estimates. A significant positive correlation would indicate that subsequent regression analysis could be used to predict true abundance based on the bottom-net sample. Abundances were corrected from the bottom-net samples (by multiplying by $\frac{\text { pond area }}{\text { bottom-net area }}$ ) to account for differences in the proportion of total surface area that the net was sampling at a particular time. For species with significant correlations, a linear regression model was then fit (true total abundance vs corrected bottom-net sample) to predict total abundance based on corrected bottom-net samples. The slope of the model would indicate if the corrected bottom-net sample was overestimating (slope $<1$; uncorrected bottom-net sample would be oversampling the population), or underestimating (slope $>1$; uncorrected bottom-net sample would be undersampling the population) tadpole abundance. In either case, the regression models could be used to estimate total abundance of tadpoles at a site based on bottom-net samples.

\section{RESULTS AND DISCUSSION}

Three species of tadpoles and one predator were sufficiently abundant to perform correlation and regression analysis. Colostethus marchesianus Melin, 1941, Osteocephalus taurinus Steindachner, 1862, Phyllomedusa tomopterna Cope, 1868, as well as aeshnid naiads (Odontata) were present in all six exhaustive samples and therefore could be analyzed. Other tadpole species present but too infrequent for analysis were Leptodactylus knudseni Heyer, 1972, L. rhodomystax Boulenger, 1883, and Epipedobates femoralis Boulenger, 1883. Correlations between corrected bottom-net samples and total abundance (from the exhaustive samples) were positive and significant in three out of four cases: $r=0.906$, $\mathrm{P}<0.050$ for $O$. taurinus; $\mathrm{r}=0.854, \mathrm{P}<0.050$ for $P$. tomopterna, and $\mathrm{r}=0.806$, $\mathrm{P}<0.050$ for aeshnid naiads. For $C$. marchesianus, the correlation was not significant $(r=0.651, P>0.050)$.

An outlier was detected in the regression analysis for $P$. tomopterna and was excluded from the final analysis (Pearson correlation for this species without the outlier remained significant; $r=0.869, \mathrm{P}<0.050)$. All regression slopes were smaller than one (Fig. 1). This indicates that the bottom-net sample was overestimating total abundance for all species including aeshnid naiads. For the three regressions that were significant ( $O$. taurinus, $P$. tomopterna, and aeshnid naiads), the models explained a large proportion of the variance; from $65 \%$ for aeshnid naiads to $82 \%$ for $O$. taurinus. 

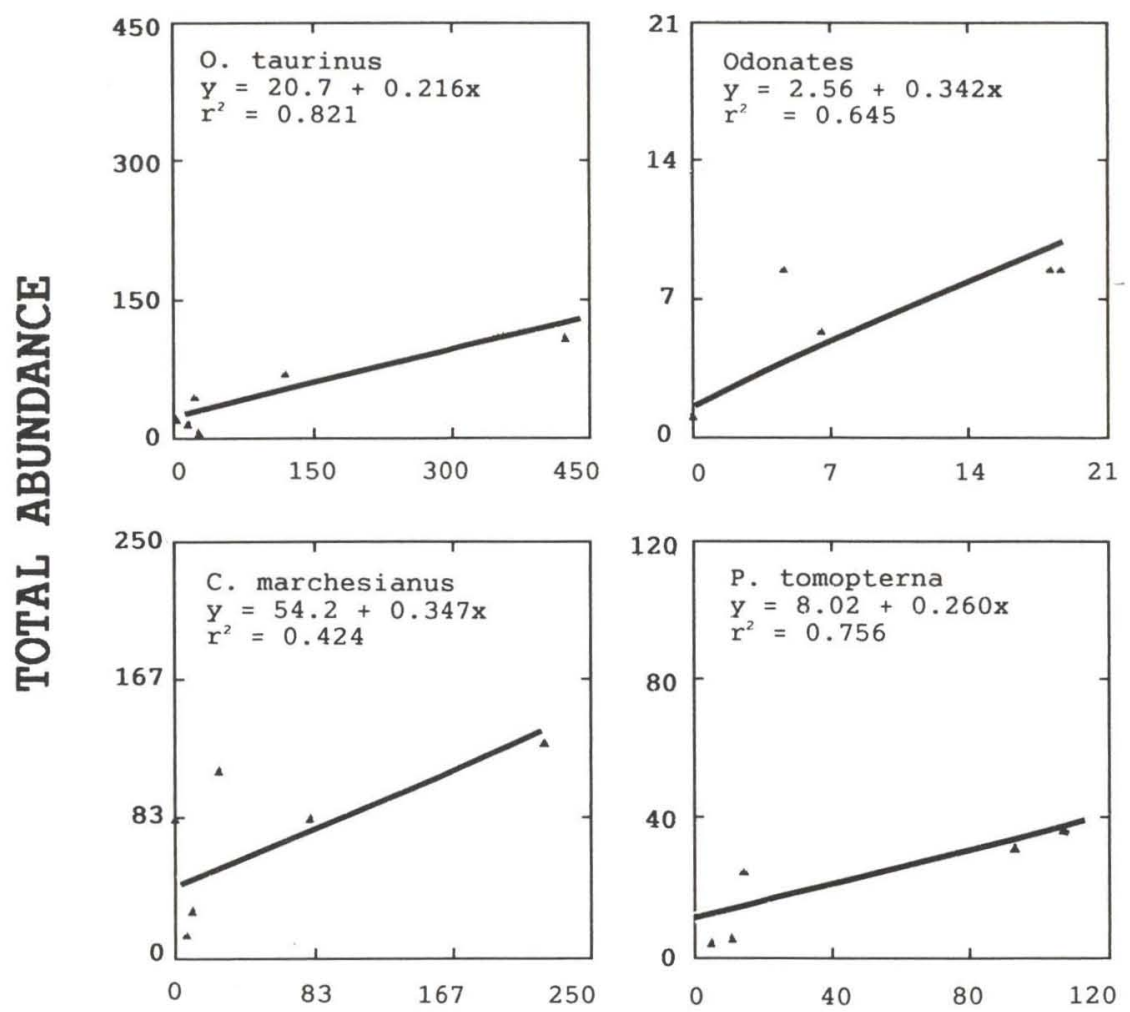

\section{CORRECTED BOTTOM-NET SAMPLE}

Fig. 1. Plots of regressons for each tadpole species and the achond natads found on the hottom-net samples. Each regression is of total abundance as determined from the exhaustive sample is the bottom-net sample abundance corrected for surface area). All regressions are significant except for C. marchesianus.

In all cases, hottom-nets overestimated the total abundance of tadpoles and naiads. This is probably due to the fact that hottom-nets were sampling a very large proportion of the total area of the pond (from 12 to $90 \%$ ). most of it open-water area. Nets were placed so that their length would pass through the longest dimension of the pond. This resulted in a large proportion of open-water being sampled compared to shallow pond hanks. Nevertheless, this method can reliably estimate total abundance. One only needs to calibrate the hottom-net samples with exhaustive tadpole counts for the particular group of ponds under study, determine which species have a significant correlation, and fit a regression model to estimate total abundances based on bottom-net samples. Bottom-nets were only used in relatively small ponds in this study; these types of hahitats are the most common ones in the area. This method, however, could be tested and calibrated in other 
types of ponds. Overall, this method has advantages over other quantitative sampling methods in that it is not time-consuming, involves very little handling of the tadpoles and or naiads, and provides accurate estimates of total abundance once the calibration is performed. Bottom-net sampling can therefore be used in large-scale surveys of small isolated ponds where total abundance of tadpole populations needs to be estimated.

ACKNOWLEDGEMENTS. This study was supported by World Wildlife Fund, Instituto Nacional de Pesquisas do Amazonia. The Smithsonian Institution. and Sigma XI. The Scientific Research Sociely. Additional support was provided from a Graduate Fellowship from FCAR (Quebec). I wish to thank O. Percira and L. dos Reis for their great help in all aspects of field work. Support during the preparation of this manuscript was provided for an NSERC (Canada) Post-Doctoral Fellowship.

\section{BIBLIOGRAPHIC REFERENCES}

AlFORD, R.A. 1986. Habitat use and positional behavior of anuran larvae in a Northern Florida Temporary Pond. Copeia: 408-423.

ALFORD, R.A. \& M.L. CRUMP. 1982. Habitat partitioning among size classes of larval Southern Leopard frogs, Rana utricularia. Copeia: 367-373.

Gascon, C. 1991. Population and community level analyses of species occurrences of central Amazonian forest tadpoles. Ecology 72: 1731-1746.

GuTTMAN, S.I. \& W. CREASEY. 1973. Staining technique for marking tadpoles. Jour. Herpet. 7: 388-390.

HERREID, C.F. \& S. KInNEY. 1966. Survival of Alaskan woodfrog (Rana sylvatica) larvae. Ecology 47: 1039-1041.

HEYER, W.R. 1973. Ecological distribution of frog larvae at a seasonal tropical location in Thailand. Jour. Herpet. 7: 337-361. . 1976. Studies in larval Amphibian habitat partitioning. Smiths. Contr. Zool. 242: 1-27.

1979. Annual variation in larval Amphibian populations within a temperate pond. Jour. Wash. Acad. Sci. 69: 65-74.

Seale, D. \& M. BoraAs. 1974. A permanent mark for amphibian larvae. Herpet. 30: $160-162$.

TURner, F.B. 1960. Population structure and dynamics of the western spotted frog, Rana p. pretiosa Baird and Girard, in Yellowstone Park, Wyoming. Ecol. Monogr 30: 251-278. 